\title{
Enhancing Organisational Competitiveness Via Social Media - a Strategy as Practice Perspective
}

\author{
Shirumisha Kwayu ${ }^{1} \cdot$ Banita Lal $^{1} \cdot$ Mumin Abubakre $^{1}$ \\ Published online: 20 December 2017 \\ (C) The Author(s) 2017. This article is an open access publication
}

\begin{abstract}
The affordances, popularity and pervasive use of social media platforms such as Facebook, Twitter and Instagram have made these platforms attractive to organisations for enhancing their competitiveness and creating business value. Despite this apparent significance of social media for businesses, they are struggling with the development of a social media strategy as well as understanding the implications of social media on practice within their organisations. This paper explores how social media has become a tool for competitiveness and its influence on organisational strategy and practice. Using the 'strategy as practice' lens and guided by the interpretivist philosophy, this paper uses the empirical case of a telecom organisation in Tanzania. The findings show that social media is influencing competitiveness through imitation and product development. Also, the findings indicate how social media affects the practices within an organisation, consequently making the social media strategy an emergent phenomenon.
\end{abstract}

Keywords Social media strategy $\cdot$ Competitiveness $\cdot$ Strategy as practice theory

\section{Introduction}

The use of social media in organisations has advanced from experimentation to mainstream level implementation (Pillet and Carillo 2016), with the aim of increasing competitiveness and gaining business value for organisations (Bughin and Chui 2013). Social media platforms are significant for enhancing competitiveness (Aswani et al. 2017) and obtaining business value as they instantaneously produce real-time information with global reach: most platforms such as Facebook has more than a billion users (Piskorski 2014). For organisations to remain competitive, they need to use social media, as it provides organisations with affordance such as communication visibility (Leonardi 2015) that were not achievable with previous forms of Information Technology (IT) (Treem and

Shirumisha Kwayu

Shirumisha.kwayu2014@my.ntu.ac.uk

Banita Lal

Banita.Lal@ntu.ac.uk

Mumin Abubakre

Mumin.Abubakre@ntu.ac.uk

1 Nottingham Trent University, Nottingham, UK
Leonardi 2012). For instance, social media enables new communication processes within and outside of organisational boundaries (Scott and Orlikowski 2012), as well as allowing customers to communicate with other customers on a scale and scope that was not achievable by previous forms of Information Technology (Gallaugher and Ransbotham 2010). Hence, information may become more visible and accessible to the public, and allow more information gathering or monitoring which suggests that social media platforms have material properties that are different from other technologies used in organisations.

Social media use has begun to thrive in organisations (Joos 2008), reconfiguring the dynamics of organisational culture, networks, and power relations (Castelló et al. 2016). Nonetheless, few studies have researched the impact of how social media provides a new context for engagement in organisations (Leonardi and Vaast 2016; Orlikowski and Scott 2008). The existing studies on social media within organisations have been mainly along three streams. First, is the body of research on social media marketing (e.g. Berthon et al. 2012; Gallaugher and Ransbotham 2010; Kaplan and Haenlein 2011). The second stream of social media research examines the predictive power of social media (e.g. Dewan and Ramaprasad 2014; Luo et al. 2013). The third stream of social media research is concerned with how organisations use social media as a strategy to achieve 
organisational goals (e.g. Braojos-Gomez et al. 2015; Culnan et al. 2010; Piskorski 2014).

Although organisations are beginning to understand the significance of social media for their organisations, they still face some challenges. For instance, how to formulate social media strategies (Kietzmann et al. 2011) and how to implement and strategically use social media strategies (Bharati et al. 2014; Kietzmann et al. 2011). Furthermore, organisations face challenges regarding how they should organise and manage social media within their organisation and what broader changes in organisational structure and processes are needed for the implementation of social media (Aral et al. 2013). Thus, taking into consideration these existing challenges, and considering the lack of literature examining these issues, it can be argued that further research to understand how social media strategy emerges and its implications on structure and processes within organisations is needed.

In light of the above, this research aims to explore: how organisations use social media as a tool to enhance competitiveness through understanding the emergence of social media strategy and its influence on structure and processes within the context of a Tanzanian Telecommunications company.

This research draws upon the 'strategy as practice' perspective using the imbrication metaphor. The strategy as practice perspective is useful for exploring a dynamic technology such as social media as it does not assume the stability, predictability or relative completeness of technology. The perspective focuses on the emergent organisational structures and processes that are enacted from the recursive interaction of people and material (i.e. technology) (Orlikowski 2000). 'Imbrication' addresses the interweaving of people and material agencies (Ciborra 2006). The imbrication metaphor helps understand how structures and processes are produced, sustained and changed. The imbrication metaphor combined with the strategy as practice perspective can help to understand the impact of social media on an organisation's strategic activities, processes and structure.

Motivated by the concerns mentioned above, this study proposes the following research questions: 1) How does social media influence the emergence of strategy, structure and processes within an organisation? 2) How does an organisation use social media to enhance competitiveness?

This research adopts an interpretivist approach to gather empirical evidence from the case study of a Tanzanian Telecommunications company by conducting semistructured interviews and documentary analysis as methods of data collection. By conducting this study, our research makes the following contributions: firstly, it provides an understanding of the emergence of a social media strategy within an organisation and the implications on its structure and processes as a result of social media influence, a topic on which there is currently a lack of literature (Aral et al. 2013). Secondly, considering that many studies on social media are conducted in western developed countries (e.g. Castelló et al. 2016; Leonardi and Vaast 2016; Scott and Orlikowski 2012), this research uses a case organisation from Tanzania, which is a developing country and thus provides a different context for study. Developing countries like Tanzania are faced with socio-economic and technical challenges which contribute to the global 'digital divide' (Mercer 2005). Thus, studies that emerge from this context where things like the internet, purchasing power and electricity supply are challenges, can be considered as novel in helping to understand issues facing organisations that have invested in new technologies such as social media. Lastly, the study emphasises social media as an example of an Information System (IS), which helps to look at ways that technology is mutually constituted with the organisational context in which it is embedded (Dwivedi et al. 2015; Leonardi 2011; Treem and Leonardi 2012). Consequently, it helps to explain the impact of social media beyond the limited focus of a traditional IS.

The remainder of the paper is organised as follows. We first discuss the literature on social media strategy and competitiveness and the relationship between technology, strategy, structure and processes. This is followed by a discussion on the strategy as practice perspective, which forms the theoretical lens for this research. Thereafter follows the methodology section which explains the research context, rationale for site selection, methods of data collection and data analysis. This is followed by the presentation of the empirical evidence and discussion on the implications for literature and practice. Finally, we conclude with limitations and insights on future research.

\section{Social Media Strategy and Competitiveness}

There is a fundamental relationship between strategy and competitiveness. Stonehouse and Snowdon (2007) suggest the choice of strategy as an important determinant of an organisation's competitiveness. Regarding social media, Piskorski (2014) defines strategy as the idea of using social media for value creation and competitive advantage. Albeit limited, some studies have explored the concept of social media strategy. For example, the study of Piskorski (2014) argues that a successful social media strategy seeks to increase an organisation's profitability through improving interaction between people and making them undertake sets of corporate functions for free. Piskorski (2014) progresses the social media strategy from existing business strategy, specifically using Porter's (2008) generic strategy, which gives organisations two sets of choices to pursue: either the differentiated social strategy, which allows an organisation to increase customer willingness to pay without a commensurate increase in cost, or the low-cost social strategy, which helps an organisation to reduce its cost without the commensurate decline in its customer willingness to pay. Also, Piskorski (2014) argues that an organisation will have a tactical 
choice once it has selected the strategy; the tactical choice is either implementing social media at a company-wide or functional level. A company-wide strategy needs structural changes, and it helps an organisation to be competitive in the long run. The functional strategy, on the other hand, is limited to a particular function within the organisation, such as the marketing strategy or operational strategy. Functional execution is not very helpful in the long run; however, due to the complexity of company-wide implementation, organisations can start with functional strategies then embark on the company-wide strategy (Piskorski 2014). The tactical choice is significant especially when considering that social media can be deployed by multiple departments within the organisation such as customer service, marketing, public relation and design (Bharati et al. 2014). Nonetheless, the use of social media in multiple functions has the potential of exposing organisations to social media risk that can have detrimental impacts on the organisation (Gangi Di et al. 2016), with issues such as privacy and security (Muhammad et al. 2017). Upon reflection of the literature and in light of the three main areas of focus of existing studies examining social media as aforementioned - social media marketing, social media and predictive power and social media strategy - it is fair to say that insofar, organisations have tended to take a more functional approach when it comes to social media and strategy (Bharati et al. 2014). For instance, owing to the significant use of social media within the marketing departments within organisations, the marketing function within an organisation would be more responsive to competition and active on social media platforms (Kaplan and Haenlein 2011).

In a different study on social media strategy, Culnan et al. (2010) outline three elements for implementing social media strategy that enables organisations to gain full business value from social media. The three elements are (i) mindful adoption, (ii) community building and (iii) absorptive capacity. Mindful adoption refers to the keen decision of an organisation to adopt social media platforms. Community building refers to the interaction maintained by the organisation with customer communities on the social media platform to retain and sustain the customer base, while absorptive capacity refers to the process developed by the organisation to source the business value from the communities on the social media platforms. Also, Culnan et al. (2010) provide guidelines for implementing social media strategy. Firstly, an organisation needs to promote the coordination of use; for instance, providing links of their social media platforms from their websites. Secondly, an organisation needs to address risk management issues; for instance, by developing a policy of social media use (Gangi Di et al. 2016). Lastly, an organisation needs to develop procedures to process unstructured transactions, for instance, linking social media with customer service. Whilst providing a useful general understanding of how an organisation may choose to implement their social media strategy, the weakness of this concept is that it focuses on the customer and ignores other issues such as the impact that the social media strategy has on an organisation's structure and processes.

Further evidence on the study of social media is provided from the work of Braojos-Gomez et al. (2015), based on firms' proficiency of using and leveraging social media for business activities and competitive reasons. In their study, the authors identified variables that organisations can use to develop social media competence which are: social competitor pressure, organisational infrastructure capabilities and IT infrastructure capabilities. Social competitor pressure is the pressure exerted by competitors on an organisation to adopt and learn social media. It is suggested that organisations tend to mimic their relevant competitors so that they do not lose their competitiveness (Sinclaire and Vogus 2011). The organisational infrastructure capabilities are essential in supporting the proficiency of using social media. For instance, an organisation with good marketing capability is better off in using social media than an organisation that has low marketing capability. Likewise, an organisation that has a good IT infrastructure capability is better off in executing their social media strategy compared to an organisation that has low IT infrastructure capability (Braojos-Gomez et al. 2015). This suggests that for a social media strategy to be successful, an organisation must respond to both the external pressure from competitors and also focus on its internal capabilities to execute its social media strategy efficiently. Thus, this study highlights that without the internal capabilities, the response to external pressures will be compromised.

The studies mentioned above have explored how social media can be leveraged to provide an organisation with business value and increased competitiveness and, to an extent, how an organisation can deal with social media. Nevertheless, these studies have failed to address how organisations reconfigure their processes and structure (Wagner et al. 2014) in the quest for developing strategies for leveraging social media to gain business value and increased competitiveness (Aral et al. 2013). Furthermore, these studies have primarily taken place in the US - Culnan et al. (2010) and Piskorski (2014) explored large companies whereas Braojos-Gomez et al. (2015) explored small businesses in the US. This necessitates the understanding of not only how social media has impacted an organisation's strategy, structure and processes, but also how social media strategies are developed in other contexts outside of the US.

\section{Relationship between Technology, Strategy, Structure and Processes}

For years, Information Systems (IS) scholarship has been concerned with the role of technology on organisational structure and processes, particularly trying to understand how people (social) and technology (material) interact to affect 
organisational strategy, structure and processes (CecezKecmanovic et al. 2014). Technology has a causal relationship with organisational structure and processes, which is located on the interaction of people and technology that consider the IS phenomena as an enactment of people's interaction with technological artefacts in their social context (Avgerou 2017). Thus, understanding the influence of technology needs a consideration of structure, process and social activities, which can provide insight on organisational strategy as well as the process of organising within the organisation. Structure can be understood as a clearly defined pattern of activity in which, ideally, every series of action is functionally related to the purpose of the organisation (Harper 2015), whereas process is a systematic series of actions directed by organisational members towards a goal (Harris et al. 2013). The central locus of processes and structure are the social activities, which define strategy (Jarzabkowski 2005).

The relationship between structure and strategy is reciprocal (Takahashi 2017) as strategy influences the structure, and structure enables, constrains and shapes strategy. Structure as a context in which decisions are made and observed (Lawton 2017) can be classified into three main dimensions that are: centralisation, formalization and complexity (Wu et al. 2010). Centralisation is the extent to which the right to make decisions and evaluate activities is concentrated (Wagner et al. 2014). Formalization is the extent to which an organisation deploys rules and procedures to guide decisions and activities (Ashkenas et al. 2015). Complexity is a situation whereby an organisation is composed of many interrelated parts. For example, an organisation that concurrently has several levels, a broad span of control and multiple geographic locations is considered as a complex organisation (Wagner et al. 2014).

Structure relates to an enacted set of rules and resources which mediate social action through facilities, norms and interpretive schemes (Giddens 1984). This means knowledge of structure elucidates social behaviour. Thus, an understanding of structure can assist the understanding of social media usage and impact since it is the interplay of social and technical factors that determine user engagement on social media (Idemudia et al. 2016). Therefore, to understand social media influence in organisations, one must consider practice, which is an interplay between people and technology, which enacts structure. Thus, the next section will explore the strategy as practice perspective as the theoretical lens for this research.

\section{Strategy as Practice}

The strategy as practice perspective is a theory that conceptualises strategy as an activity. Jarzabkowski (2005) explains strategy as practice as concerned with strategy as situated, socially accomplished activities constructed through the actions and interactions of multiple actors. Similarly, Wade and Hulland (2004) suggest that strategy as practice is concerned about how strategy is done, who does it, what they do, how they do it, what they use and what outcomes it has on shaping strategy. This view considers both internal and external factors of an organisation; for example, practitioners are both people within an organisation and outside of the organisation who are involved in the situated (strategic) activity.

The strategy as practice perspective provides a suitable angle to understand how technology such as social media can affect strategy, processes and structures within an organisation for the following reasons. Firstly, it contributes to the long course of understanding of the interplay between people and material arrangement in an organisation. The strategy as practice perspective has done so by considering broad research parameters that are practitioners, practice and praxis (Whittington 2014). Secondly, the strategy as practice perspective is relevant as it can unravel the complex dynamics of strategy as it considers the social context in which the strategy is formulated; thus, it gives insight on a reality that is dynamic and complex. Furthermore, because social media is intertwined with social and technical elements (Scott and Orlikowski 2014), the strategy as practice perspective offers a valuable means of understanding its role in an organisation's strategy as it focuses on practice which is an interplay between people and technology in organisations (Whittington 2014).

Considerably, the strategy as practice theory is suitable for exploring the influence of social media on organisational structure and processes as it focuses on activities (Orlikowski 2007). It is suitable because it considers different elements, as abovementioned, which are practitioners, practice and praxis. Huang et al. (2014) explain them as follows - the practitioners are actors who shape and actualise an activity, including actors within the firm and external actors such as competitors and regulators. The practice relates to the institutionalised routines that guide activity based on traditions, norms and procedures that exist both within and beyond organisational boundaries. The praxis is the actual activities of creating and enacting a process, which may be different or similar to the institutionalised routines but, due to the interpretation of practitioners involved and the prevailing situation, they can disrupt the routinized practice. Thus, by considering these elements of strategy as practice, which are practitioner, practices and praxis, it provides the researcher with the ability to unravel the reality that is multiple, complex and dynamic (Jarzabkowski 2005).

Also, the strategy as practice theory is rooted in critical realism, which considers people (social) and technology (material) as separate entities brought into a relationship with one another and inseparable through human activity over time (Archer et al. 2013). Thus, scholars such as Leonardi (2011) suggest that using a critical metaphor addresses the interweaving of human and technology (material) in an imbrication manner, which assumes the inherent separation between 
human and technology agency while simultaneously indicating their synergetic interaction. Therefore, for the critical realist, the human and technology affect and mutually shape each other through imbrication in social action. For instance, the imbrication of human and material agencies creates a new work practice in an organisation. This is where a new work practice results from the previous imbrications of human and material agencies. Considering this, the imbrication metaphor is useful for our study, as it will enable us to understand the change and stability as well as appreciating the relationship between the social and material about how social media affects an organisation's strategy and its structure and processes.

The arguments above position our research with the ability to explain the reality of contemporary organisations, which are highly digitized with technologies such as social media that are inherently dynamic and multifarious (Scott and Orlikowski 2014).

\section{Methodology}

Following the research aim of understanding how social media is used to increase competitiveness and its implications on strategy, structure and processes led to the selection of a case study method. A case study method provides a valuable means of gaining an in-depth understanding of a real-life phenomenon through combining the research phenomenon with its context, consequently providing a richer understanding of context and process in which it is enacted (Yin 2013). The case study is guided by the interpretivist philosophy, which argues that knowledge is socially constructed through languages, shared meaning and consciousness (Orlikowski and Baroudi 1991; Richey et al. 2018). Considering practices are accomplished social activities, understanding the social construction of activities through the interpretations of the people involved helps to understand how strategy, structure and processes are enacted. The interpretivist philosophy is used as it helps to study a phenomenon in its natural settings, enabling the researcher to set aside his/her predetermined views that may obscure the process of gaining new knowledge; hence, it aims to eliminate bias (Orlikowski and Baroudi 1991). Through the elimination of researchers' bias and the inclusion of the practitioners' (the participants') interpretation of their reality, interpretivism offers the best insight of the reality in activities that shape the reality of an organisation.

\subsection{Research Context}

The case study for this research is a telecommunications (telecom) organisation in Tanzania named KISU (a pseudonym used). Considering the nature of this study, it naturally requires insight from within KISU to understand how social media affects strategy, structure and processes. Thus, this study has used one of the four main Tanzanian telecom companies to gather insight from within. For this research to be able to provide the context and show the competitiveness of KISU, it also requires an overview of social media activities from Tanzanian telecom organisations that are Vodacom, Tigo, TTCL and Airtel.

\subsection{Site Selection and Access}

The selection of the case was based on selecting an industry with high adoption density of social media. This choice was informed by the work of Braojos-Gomez et al. (2015), which highlights that organisations adopt social media due to social competitor pressure, as well as by the findings of Culnan et al. (2010) that social media adoption density is dependent upon industry. Furthermore, the selection of the telecom industry followed Belasen and Rufer's (2013) suggestion that high tech industries such as the telecom industry are quicker in adopting new technology as they are faced with fast shrinking product cycles.

In addition, Tanzania was selected as an alternative context for exploring the influence of social media in organisations since many existing studies examining the impact of social media are conducted within the western developed context (Parveen et al. 2015). Tanzania is an emerging market, which experiences the growth in demand of using globalised technologies such as social media, internet and mobile telecommunication. Thus, insights gained from such a context will be invaluable to both academicians and practitioners.

\subsection{Data Collection}

This research collected data in two main ways, which are document sources and semi-structured interviews. The document sources were used for industry analysis; the main type of document source were virtual outputs. Bryman and Bell (2015) assert that organisations are significant producers of virtual documents which tend to play an important role in constituting an organisation's image and identity. The advantage of this method is that the data are publicly accessible and well disseminated. Thus, this research used data from the websites of the respective companies as well as their official social media accounts to provide a landscape analysis of social media usage by telecom organisations in Tanzania.

Furthermore, semi-structured interviews were used to collect data from KISU. Semi-structured interviews are useful as they allow a researcher to hear what the informant says on the topic areas identified by the researcher (Parveen et al. 2015). The interviews were carried out with the staff and managers of KISU; the rationale for doing so is because processes are something that an organisation and its multiple actors do (Golsorkhi et al. 2015). The selection of managers as informants was because the managers are involved in the decision making 
regarding social media while staff are the actual implementers and their action is significant to the outcome of strategy. Although there were questions to guide the interviews, the interviews flowed with questions that arose from the explanations of the interviewees. In general, each interview would start by seeking to understand the background of the interviewee in the company as well as his/her roles and responsibility within the company. Thereafter, the interview proceeded to understand how they used information technology and then sought to know how they used social media and the rationale behind this. Interviewees were encouraged to open up with honest responses from the start of the interviews as they were briefed on the reason for the interviews.

Twelve semi-structured interviews were conducted with different informants from KISU who work in different departments, i.e. Marketing, Public Relations, Product Development, the IT department and Finance (See Table 1).

The first author, who is of Tanzanian dissent, conducted the interviews. The interviews were done one to one, to remove other interviewee bias and preserve the confidentiality of the informant. Each interview lasted for approximately an hour. The language used in the interview was both Swahili and English, depending on the respondents' preferred language and the comfort level in each language. In Tanzania, people mix Swahili and English when they speak, so the interviews were conducted in English and Swahili. Also, the interviews were recorded upon the interviewees' consent for the data analysis.

\subsection{Data Analysis}

The analysis was conducted using an inductive approach that collects data and explores it to extract themes and issues that arise to concentrate on (Glaser and Strauss 1967). The analysis was done through content analysis and structuring data using narratives. The content analysis was done for the virtual data

Table 1 Interviewee profile at KISU

\begin{tabular}{ll}
\hline No & Profile \\
\hline 1 & CEO \\
2 & Manager IT Operation \\
3 & IT Staff \\
4 & Marketing Manager \\
5 & Marketing Staff \\
6 & Finance Manager \\
7 & Manager Network Development \\
8 & Manager Product Development \\
9 & Human Resource Head \\
10 & Human Resource Staff \\
11 & Regional Manager \\
12 & Public Relation Officer Communication \\
\hline
\end{tabular}

collected. The narrative structuring was used for the interviews. The interviews were transcribed and translated for analysis. After transcription, a thematic analysis was applied to the interviews transcripts; thus, excerpts from the transcripts were linked by a common theme which enabled categorisations that facilitated narrative structuring. Coffey and Atkinson (1996) explain narrative structuring as an account given on the experience of a narrator in a sequential way, indicating the flow of related events which, when taken together, convey meaning to the researcher and its significance for the narrator. Narrative structuring is done through forming a coherent story from data collected during an interview. The significance of this is that it helps to remove fragmentation of data and it also takes into consideration the social and organisational context in which events occurred (Saunders et al. 2009). In considering the social and organisational context, the narrative style can highlight points made, what they symbolize and how they reveal specific issues such as organisational politics, culture and change.

Our data analysis consisted of four main stages that were: summarising, clustering, displaying and narrating (Pan and Tan 2011) to show the strategic activities and their situated context (Jarzabkowski 2005). The key points from every interview transcript were summarised as a means of reducing the bulkiness as well as having a manageable content. The summaries were coded with a reference to the original transcript.

After summarising, the subsequent stage was to cluster the data based on the summarised content. The clustering eased the process of analysis by showing the origin of the content and enabling the formulation of the themes. For example, identifying competitive elements influenced by social media and the influence of social media on processes.

Furthermore, we displayed the clustered data according to the themes that emerged: the display of data enabled us to form four sections that are: social media use in Tanzania, social media and the telecom organisation, social media as a tool for competitiveness, and the influence of social media on practices. The following is a narration of the findings based on the themes identified.

\section{Findings}

\subsection{Tanzania}

Tanzania, located in East Africa, has an estimated population of 44 million people [ 2012 census] with per capita income of $£ 345$ (MOF 2017). Around $90 \%$ of the population are smallscale farmers (Sedoyeka et al. 2008). Over the last 15 years since 2001, the country has experienced impressive economic growth averaging 6-7\% annual growth. However, there is still a significant part of the population, approximately 12 million, 
living in poverty with earnings of less than $£ 0.50$ per day (World Bank 2017). The economic growth is at large contributed by the communication sector, which recorded the highest growth compared to other economic activities with a growth rate of $20.6 \%$ (MOF 2017). This includes growth in technology investment, which makes social media a contemporary phenomenon for investigation.

\subsection{Telecommunications Industry}

The largest and the oldest fixed telecom company in the country is Tanzania Telecommunication Company Limited (TTCL), which is owned by the government. It has 129,597 fixed line subscribers (TCRA 2017). The company enjoyed the luxury of monopoly up until the mid-1990s when the country adopted market liberalization. The telecom sector has seen growth in mobile phone services with the current seven companies that are Vodacom, Tigo, Airtel, Halotel, Zantel, Smart and TTCL. The total number of telecom service subscriptions in Tanzania is $40,173,783$, which is equivalent to $80 \%$ of the population. In addition to the growth of mobile services, Tanzania has also experienced growth in Internet penetration. There are 19,862,525 internet subscribers, which is almost half of the mobile subscribers using the internet. The telecom companies are the major Internet suppliers in the country. Figure 1, shows the percentage of telecom subscription in the country whereas Fig. 2 shows the Internet penetration in Tanzania. The impact of this mobile and telecommunication growth prompts citizens to learn new ways of exploiting this technology in a wide range of styles (Rana et al. 2017) such as communicating and seeking information through social media.

\subsection{Social Media Use in Tanzania}

Social media is widely used in Tanzania. Although social media usage statistics are vague, they indicate and highlight the growing use of social media in the country. According to GlobalStat, Facebook is the most-used social media platform in Tanzania followed by Pinterest, Twitter, Instagram and YouTube. Fig. 3 below shows the percentage usage of social media in Tanzania. Regarding numbers, Facebook has an estimate of 6.1 million subscribers in Tanzania (Internet World Stats 2017). While these statistics indicate the growth of social media, from hindsight, it shows that Instagram and WhatsApp are more popular and widely used, almost reaching the levels of Facebook usage.

To elaborate upon the figures above and to explain the context of social media usage in Tanzania further, the following reflection from a marketing manager of KISU is provided:

'The Tanzania we have now is different from one a decade ago. A decade ago you could hardly find 2 million Tanzania [ns] using internet but now we have more than twenty million internet users. In addition, it is not only people in urban areas who are using it but also people in the villages - you will find people having WhatsApp, Facebook and they post their issues there. Therefore, we said we cannot be left behind. We should use these social media to capture that market'.

From this explanation, we see how the growth of the Internet has enabled and led to the growth in the use of social media in both urban and rural areas, and that has turned out to be a significant market opportunity for telecom organisations, as well as a sphere for increased competition.

Also, the use of social media can be perceived as somewhat addictive and of considerable importance to consumers. A
Fig. 1 Telecom Subscription Market Share in Tanzania. Source: (TCRA 2017)

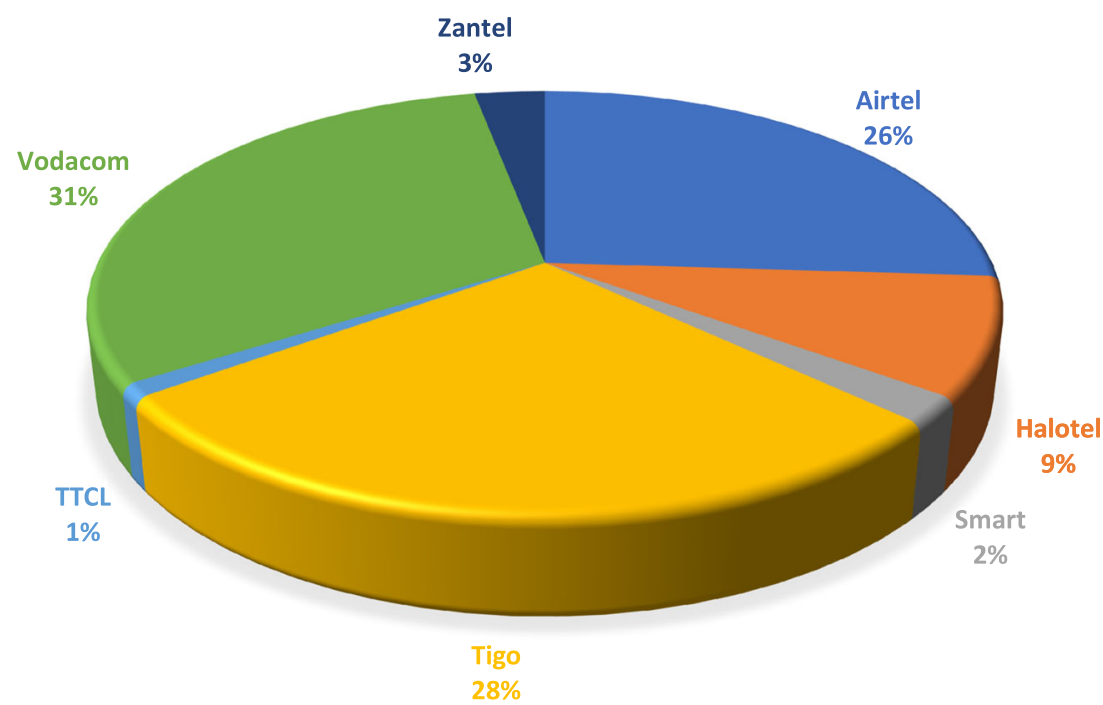


Fig. 2 Trend of Internet Penetration in Tanzania. Key: Yaxis; LHS - Population in millions, RHS- percentage of population. X-axis; Years. Source; (TCRA 2017)

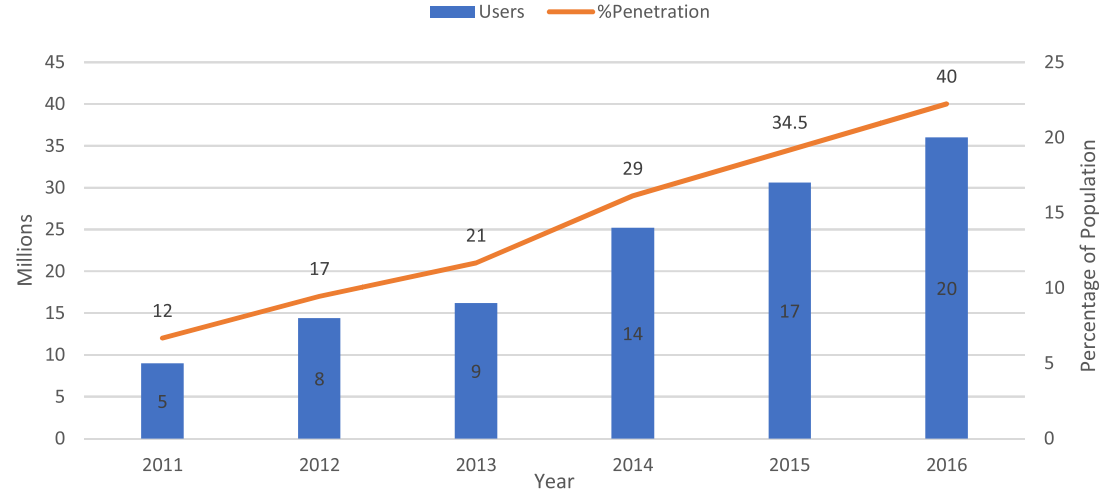

\subsection{Social Media and the Telecom Organisations}

marketing employee explains the behaviour of social media users as follows:

Social media is primary; when someone wakes up in the morning the first thing to look is updates on social media. Then if social media is the first thing, we should provide it to our customer'.

Taking into consideration this behavioural change amongst consumers - due to the usage of social media - and the growing usage of social media in Tanzania overall, telecom organisations would be enthusiastic with what new affordances social media can equip them with, with the aim of increasing their competitiveness and business value.

Telecom organisations in Tanzania are active users of social media platforms. Table 1 below shows the telecom organisations in Tanzania and the platforms in which they engage. These telecom organisations have official accounts on every major social media platform including Facebook, Twitter, Instagram and YouTube. Two of them have official accounts on other social media platforms. TTCL, for example, has an account on Google + while Tigo has an account on LinkedIn.

The major competition on social media platforms is concentrated amongst three companies that are Tigo, Airtel and Vodacom. Table 2 below further reveals that Facebook is the largest platform regarding number of users, followed by
Fig. 3 Social Media Use in Tanzania. Source: GlobalStats 2017

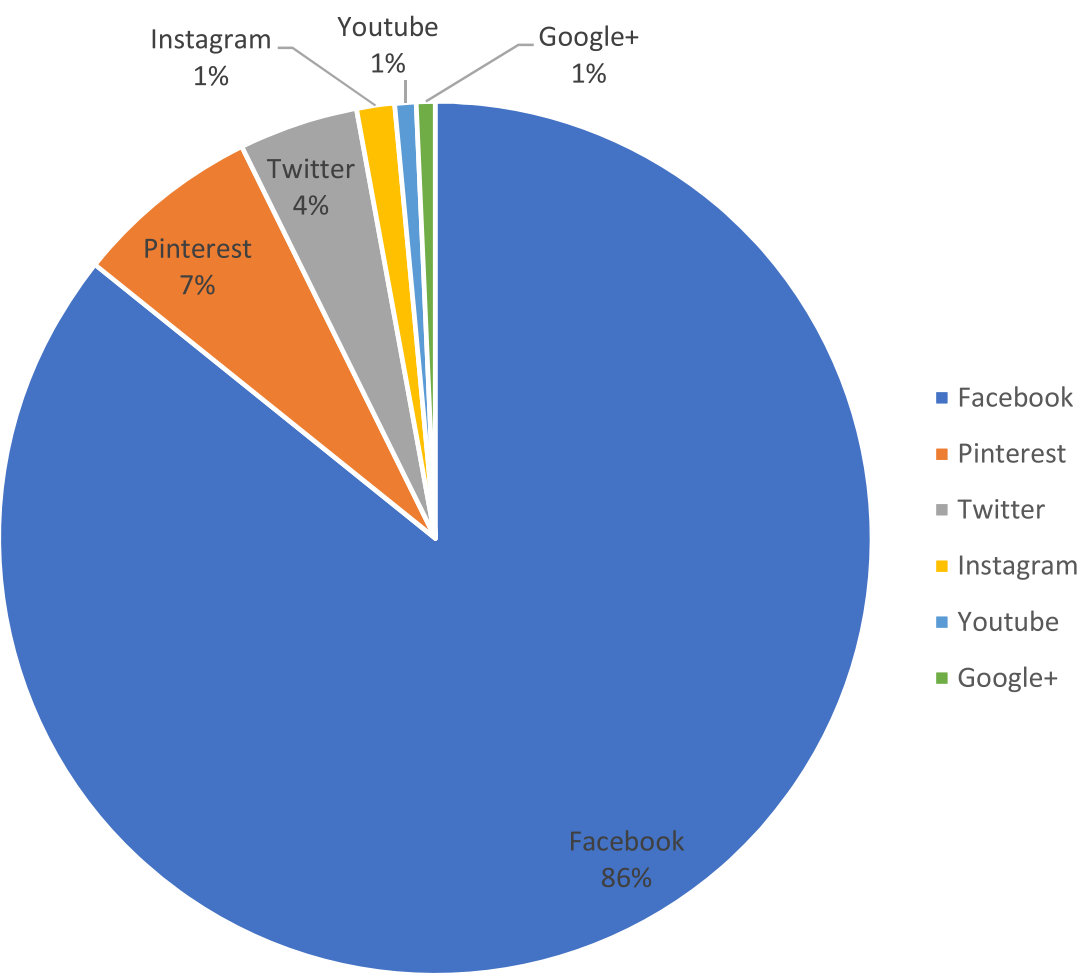


Table 2 Social media presence

\begin{tabular}{llllll}
\hline & Facebook (Page likes) & Twitter (Followers) & Instagram (Followers) & YouTube (Subscriber) & Other platforms \\
\hline Airtel & Yes $(1,086,918)$ & Yes $(197,000)$ & Yes $(209,000)$ & Yes (2209) & LinkedIn (814 followers) \\
Tigo & Yes $(1,418,168)$ & Yes $(253,000)$ & Yes $(313,000)$ & Yes (5918) & G+ (182 followers) \\
TTCL & Yes $(55,735)$ & Yes $(4841)$ & Yes $(6391)$ & Yes (56) & Yes (2799) \\
Vodacom & Yes $(874,903)$ & Yes $(195,000)$ & Yes (203,000) & . & \\
\hline
\end{tabular}

Instagram, Twitter and lastly YouTube. Noticeably, the results of leadership in a platform did not differ with platforms. For example, Tigo leads in all platforms, whereas Airtel followed in all platforms while Vodacom did not have a lead over Airtel in any platform except on YouTube.

All telecom organisations similarly use these platforms. For example, they all used the platforms to engage with their customers, to inform their customers about the activities of their respective organisations as well as to advertise their products and services. For example, Airtel will advertise their 'Hatupimi bando', Vodacom will do with 'Haliishi bando', Tigo will do 'Halichachi' and, TTCL will do 'Toboa Bundle'. All these are flagship service packages for respective firms, advertised on their social media platforms, containing similar themes and their names are related in meaning. In respective order, they literally mean, 'we do not measure', 'it does not end', 'it does not expire' and, 'go through'. These service packages are promotional packages, which enable users to save expenses on communication services. For example, a bundle will provide talk time (minutes), internet data and messages. Customers are enticed to purchase the service packages to lower their communication cost. Often a service package lasts $24 \mathrm{~h}$; some may provide free internet during the night once you have purchased the package or any offer that a telecom company believes will attract customers. Fundamentally, telecom organisations link social media platforms with their service packages. Table 2 below shows how telecom organisations offer free data service of usage of selected social media platforms when customers purchase their service packages. Interestingly, all the companies provide free Facebook usage, which may be because Facebook is the most used platform. WhatsApp is the second most provided offer, as Tigo and TTCL offer it for free. A point to note is that when a company states that it offers free social media, this means that they do not charge for data (internet) for usage of that platform. Also, when comparing Tables 2 and 3, TTCL has the least number of followers on the social media platforms. This may be because TTCL is trying to gain a market share on the platform through offering additional social media platforms for free.

\subsection{Influence of Social Media Practice on KISU}

From the data collected it became apparent that the influence of social media on strategic activities within KISU is diverse. Social media appeared to influence marketing activities such as promotion, advertising, sales, as well as product development, feedback, information sharing, outsourcing and structure. To understand the influence of social media in the organisation, this section will present some of the areas that social media has influenced within KISU.

Firstly, social media has influenced the sales processes of KISU. The advertising and promotion, which is done through social media, is acknowledged as a factor for increasing the sales processes within the organisation. A branch manager of KISU explains how social media platforms have changed his way of conducting sales, stating the following:

'I get many customers because I broadcast on WhatsApp groups, then people respond. Bring me a sim card; others people will say do this for me. Whereas before I had no such opportunity. I had to go to the street with a loud music, and then say you can get sim cards here. This would entail me obtaining a permit from the council; also, I incur cost of petrol for generators. Now I do not incur all this cost. I just send my message to the group. I can design my message and send it to group one, group two and so on. From that I can get several customers at a go'.

Table 3 Social media offers

\begin{tabular}{lll}
\hline Company & Types of offers & Service Packages \\
\hline Airtel & - Free Facebook & Hatupimi Bando (we don't measure) \\
& - Free YouTube & \\
Tigo & - Free WhatsApp & Halichachi (It does not expire) \\
& - Free Facebook & \\
TTCL & - Free Facebook & Toboa bundle (Go through) \\
& - Free WhatsApp & \\
& - Free Twitter & \\
Vodacom & - Free Instagram & \\
\hline
\end{tabular}


The marketing staff and product development manager also associate the provision of free social media as a sales factor. KISU, like other companies, offers some selected social media platforms for free. Because the majority of Tanzanians have low incomes, the free offers tend to appeal to a significant portion of the population. The companies offer free access to social media platforms only when a customer buys their 'selected product'; for instance, the service packages identified earlier. Thus, free social media is a promotional tool to drive the sales of KISU. The statements below reflect this:

'We use social media as a sales factor. When we say we are offering free social media, we first need you to buy our bundle and it is when we are giving you. So, on buying that internet bundle someone can go on Google and surf but will always go on Facebook and WhatsApp. So, we tell you to use Facebook and WhatsApp free but first buy the internet.' - Product Development Manager

'Providing free social media, it has helped a lot in people buying our products'- Marketing Staff

Secondly, social media is helping information sharing within the organisation. For large organisations such as KISU, which has more than a thousand staff across the country, sharing information regarding the organisation is at times difficult due to the bureaucracies and the centralisation process of disseminating information; consequently, people hoard information. KISU has several departments and branches across the country. In their structure, the public relations office, which works closely with the marketing department, are the custodians of the company communication. Information within KISU was concentrated in this department, and when they wanted to share it, it was difficult as not all the staff within the organisation had access to traditional communication devices such as computers or desk telephones. However, with social media which is accessible by most people via mobile devices, has influenced the dissemination of information within the company as staff can easily share information. For example, previously, some people from other departments such as Human Resources could not understand the new products being offered by the company but now, because information is shared, they know about the new products and they can efficiently assist customers/interested parties with information about products at an individual capacity since they now have information. Similarly, social media has improved how the company shares information with the public. When KISU wanted to communicate with the public, they would typically use press conferences or television as a means of sharing information. However, this was not as effective and efficient as social media. For instance, providing information via traditional press such as a magazine would involve a consumer having to buy a magazine and opening several pages to find the information. Thus, information reached few people. Nevertheless, now with social media, it is easy for the company to share information with the public and get a response. The following narratives from the Human Resource Manager and the Public Relations Manager can be considered to grasp the influence of social media on the sharing of company information:

'There are things which we put on social media platforms such as new products, new information. Previously, only commercial people knew information. Now we want all the business information to be known by everyone in the organisation, as we are here to support the business. As HR, we support part of the business. We suggested that information should be placed on intranet and social media platforms. We have 4G, we are doing this and this, we post it on twitter, Facebook. For instance, when we HR want to employ a professional, we place it on twitter, Jami forum, Facebook; we post on these platforms'. -Human Resource Manager

'We have lots that we share directly through our social media accounts of Facebook, twitter and Instagram. We use those platforms to communicate with many people. For instance, today, we have announced a job. You know that by the end of the day the information will reach many people with minimum cost compared to a page on gazette that cost three million for a single day. Therefore, the advantage is significant. First, the message spreads quickly, second, the message goes to the right people because it goes to the youth who are graduates and they are looking for those opportunities. For an advert that has gone today by the end of the day, you can receive $100+$ applications. Different from the gazette which a person needs to buy, then find the page until responding it takes a lot of process. Through social media, the advantage is that the message spreads fast and you get quick response. Feedback is important to us and we use it effectively' - Public Relation Officer

Thirdly, social media has enhanced KISU's process of obtaining feedback from consumers, which is strategically important. Previously, KISU used to collect feedback through traditional means such as through suggestion boxes in their offices. They also received feedback through their call centres. However, now KISU gets feedback from customers and staff through different social media platforms. The feedback obtained through social media channels has a different impact compared to the way feedback was obtained previously. The feedback on social media is visible to other customers, competitors and staff. Previously, feedback would not be dealt with in an urgent mode; some of it was there but never get any response, but now feedback is taken seriously. The communication custodians in KISU - that is Public Relations, 
marketing and customer service - monitor the feedback and provide responses. Moreover, staff at their individual capacities visit the social media platforms to see the feedback, especially on matters with which they are concerned. For instance, a network developer when he visits the platform, can understand when people complain about network problems in certain places and can, therefore, act either by offering suggestions of what customers can do or respond to it by any other means such as making sure the network connection works well. Thus, the feedback obtained from social media platforms feeds across different processes within different functions such as management, human resources, network control and product development within the organisation. Moreover, the feedback has led to additional processes and changes being introduced within KISU to enable the reception of feedback obtained from the social media platforms. For example, KISU have had to make changes to the call centre so that the feedback from the social media platforms can be visible to the people in customer services. Therefore, the feedback helps KISU to see how they have performed. Also, it enables them to reflect on their weaknesses. The following statements highlight the significance of feedback originating from social media platforms:

'The good thing with social media for example WhatsApp Facebook etc. As I said first you, there are some feedback that you get for example from the Facebook okay. In addition of that, you can see how you can put in your strategy in the bigger strategy. Also from WhatsApp you might get very wonderful ideas from different people within the organisation what do they think how the organisation should run. Okay, because from the definition of organisation is a collection of people to achieve goals. Okay so you can take these ideas and transform them into strategy. In cost free or less cost but at the same time efficiently and effective communication' - CEO

'HR we gain a lot, for instance when marketing post something on social media people react positively or negative. When a customer laments about your customer service, a training officer can see and know what sort of customer training is needed. A recruitment person can see and know what sort of people are not needed in the company. Therefore, on our recruitment process we work on the comments that originate from customer. In addition, we develop our trainings from the comments of our customers.' - Human Resource Manager

KISU has an organogram that shows its structure as not having a position/job in the field of social media. The process of handling social media requires some sets of skills such as graphic design and content development. Such skills are not available within KISU. Thus, KISU has outsourced some of the activities associated with handling social media platforms. The arrangement of managing social media is very informal. For example, the current outsourced 'people' do not have a formal agreement - they are just there to help. Therefore, KISU is now working to formalise the outsourcing, training internal employees as well as finding a position for people who would handle social media. The following statements from public relations and marketing, who are the custodians of social media within KISU, provides insight on how social media has been outsourced:

We have outsourced some of our social media activities, there is someone who helps to develop content, because we don't have an internal who can make graphics that can appeal nicely to customers and brand engagement' - Marketing Staff

'Our program next year is to engage people from outside and collaborate in running these social media accounts in a more competitive way. Because the way we are running them now it is a low scale in resource wise we have one person. Sometimes we lack time for creative ideas. When you look at social media they depend a lot on ICT technological skill for instance, ability to design, develop and create content. It is hard to have this ability as communication people find it hard to multitask in that sense. Our education does not give us the opportunity to have wider understanding on ICT'- Public Relations Officer.

\subsection{Social Media as a Tool to Enhance Competitiveness}

The presence and rivalry between telecom companies have influenced organisations to use social media for business purposes and competitive reasons. The interviews with staff and management from KISU highlight that KISU mimics social media activities of competitors to maintain their competitiveness. One of the ways that telecom organisations in Tanzania use social media to maintain their competitiveness is through offering free usage of social media platforms without charging the data allowances (see Table 2 on types of offers). KISU has imitated this move from other competitors and done things a little bit differently, by offering free usage also on other social media platforms. Telecom companies in Tanzania pride themselves in providing free social media access because they are the major internet service providers; thus, because users connect to the internet to use social media platforms via their network infrastructure, they automatically assume an intermediary role between social media platforms and users. This is the reason you can hear telecom companies in Tanzania say for instance, 'we offer free Facebook', 'we provide free Facebook and WhatsApp'. The following extracts from 
interviews by the product development manager and marketing manager highlight this:

'There are different strategies to win the competition. You find one operator was providing Facebook only; come another operator is providing Facebook and WhatsApp. Us we provide almost all social media. Therefore, you look at the weakness of your competitor and then you find a way to adjust better than your competitor. Other competitors have restricted streaming; we also have restricted streaming'. - Product Development Manager

'It's the market itself that shows that these social media are becoming now the good thing, so that you want to succeed, you want to be competitive you need to put yourself having these free... our competitors are also offering them free' - Marketing Manager

Furthermore, and regarding imitation as a means of sustaining competitiveness, KISU uses social media to brand itself as a youthful organisation to be able to compete with other telecom companies to attract younger people who are the major users of social media and the data (internet) service within Tanzania. The younger people in Tanzania are driving demand for internet services. The following explanation from the public relation officer can be considered regarding this:

\section{'We want to change our brand image from that of old to that of youth because we know we shall make business. The demand comes automatically, Vodacom, Tigo have done so why not us? Therefore, we must compete with them. We said we should not remain behind. You can say this is the foundation why we are on social media. There is an automatic demand. The demand shows our com- petitors they are doing why not us? Nevertheless, we also see there is a room for more business that if we follow this approach there is a youth segment, which we know they are big users of social media'- Public Relation Officer}

Social media is influencing competitiveness in how products are developed. The two main products of telecom organisations are data and voice services. From these products, the organisation can produce different bundles or service packages such as the ones shown in Table 2. When the companies create their packages, they have in mind their customers and competitors. The youth are susceptible customers, given the high unemployment rate and their desire for quality/trendy products: this demands organisations to develop products that have quality, and they are affordable. Furthermore, social media content such as streaming and video requires high-speed internet. Such considerations influence the development of products; for instance, the provision of $4 \mathrm{G}$ services that provide a faster internet connection compared to $3 \mathrm{G}$ or $2 \mathrm{G}$. If a telecom company does not offer good internet services, customers will lament on social media platforms, and most of them will shift to other operators. The product development manager and marketing manager state the following:

'The challenge is that this market is very sensitive because it is the youth who use social media. When you develop a product for youth, you should be keen on quality, on trend, reduce restrictions and make sure it is affordable. Therefore, you find the profit margin from social media product is very small, as I have said we provide social media services free and we do not have restrictions'- Product Development manager

'We are in a competitive environment when you give a customer a product that is not satisfactory they will go to another operator and at the end of the day, you will not benefit. Therefore, we must go with the requirements that a customer needs on social media. Specifically, we target a group which social media is their lifestyle Marketing Manager

\section{Discussion}

In this section, and in line with our research questions, we use the strategy as practice theory to explain how and why a Tanzanian Telecommunications organisation uses social media strategy to enhance competitiveness and its influence on structure and processes. Our first research question aimed to investigate how social media influences the emergence of strategy, structure and processes within an organisation. Our findings reveal that the online community is significant to the strategic practice of KISU. Table 2 shows the size of the community (followers) that the telecom organisations have been able to amass on social media platforms. This community is relevant as they are the first recipients of information from the telecom organisation: they are the ones who provide feedback and share the organisation's content with other social media communities that are not direct followers of the organisation. From the strategy as practice perspective, attention is given to the activities (Jarzabkowski 2005). For instance, one of the activities within KISU's online community is the provision of feedback, which we learn from the Human Resources manager that it feeds into the company's recruitment and training processes. Such practices underscore the importance of the online community to the social media strategy of KISU. This finding is consistent with prior research that has studied the role of online communities in social media strategy. For example, Culnan et al. (2010) emphasised the significance of online community as a foundation for a successful social media strategy. The presence of an online community to an 
organisation is crucial to the extent that some organisations have used spammers (fake followers) to insinuate the value of their organisation (Aswani et al. 2017). Despite this, Piskorski (2014) accentuates the role that these communities play in undertaking organisational functions; consequently, creating a recipe for organisational value and competitiveness.

Additionally, the provision of 'free social media' is a key significant finding. This is a situated practice of telecom organisations in Tanzania in the sense that it is inseparable from the context of Tanzania. Considering the strategy as practice perspective, strategy is a situated activity, which means it is shaped and shapes the context in which the activities occur (Jarzabkowski 2005). The Tanzanian telecom organisations claim the provision of free social media because of their monopoly on internet infrastructure within the country, which gives them an intermediary role between social media users and social media sites. On the other hand, free social media emerges from the context of Tanzania where there has been a rise in social media usage as well as high rates of unemployment among the youth; such a combination of factors explains the growth of the free social media strategy of the telecom companies in Tanzania. Understanding key factors influencing consumer behaviour in different countries such as Tanzania is imperative for better appreciating the context in which such behaviour is exhibited. As has been wellacknowledged in IS research, the knowledge of context is crucial as it helps to understand social factors such as people's attitude, which are central in understanding behavioural intentions and usage behaviours (Dwivedi et al. 2017).

Strategically, the free social media has enabled telecom companies to strengthen the competitiveness between themselves with the acknowledgement that free social media helps customers to buy their products (service packages). For example, the marketing manager and product development manager of KISU assert how free social media use has enhanced their brand as well as increased their sales. Jarzabkowski (2005) explains situated practices as activities embedded in the context and socially constructed by actors in interaction with the situated features of that context. These embedded activities are strategic and have consequences on the direction and survival of the group, organisation or industry (Jarzabkowski et al. 2007). Considering our case, we see telecom organisations constructing a social term (practice) 'free social media', and this has implications on sales in the organisation as well as retention of customers.

Furthermore, social media has invigorated some processes within KISU such as information sharing and the feedback process. Through stimulating those processes, social media has enhanced KISU's effectiveness within the organisation. For instance, the information sharing process within the company provides affordances that previous technologies could not achieve with efficiency and effectiveness. The feedback process makes the communication visible, highlighting the visibility of affordance of social media (Leonardi 2015; Richey et al. 2018), and ultimately increases accountability of staff and organisation. Also, the process of obtaining feedback is identified as the main reason for an organisation to adopt social media (Kapoor et al. 2017). For example, the CEO who oversees the overall strategy of KISU, has stated how social media has enabled him to efficiently source ideas from different people within and outside the organisation, which in turn it assists him in the development of strategy. The invigorated processes demonstrate an influence of social media on existing processes, which shows how change happens in an overlapping manner. The new (invigorated) processes comprise elements of the past processes. In other words, this shows how processes occur in an imbricative way. The strategy as practice theory looks at how different agencies (social and material) interact and mutually affect the organisation; in this case, we see how when pre-existing practices interact with social media they charge (invigorate) the processes. The invigoration effect of social media on organisational processes is observed in other industries such as the tourism industry whereby social media power charged the ranking and review mechanism (Scott and Orlikowski 2012) as well as marketing processes (Kaplan and Haenlein 2011). This implies that the effect of social media on processes is dependent on context, meaning that social media might have a very efficient impact on particular processes in one context but also different impact in another organisational context. Also, this shows how strategy and processes emerge from existing processes and context which tallies with the strategy as practice perspective that perceives strategy as an emergent activity (Whittington 2016).

Additionally, the use of social media creates new practices at KISU: both individual practices and shared (organisational) practices. Examples of individual practice include a branch manager's initiative of selling through social media groups rather than using the street campaign that requires significant effort and resources. Shared or organisational practices include the management of social media sites through customer service. The strategy as practice perspective perceives the use of technology as enactment rather than appropriation: the enactment helps to understand the ongoing use of technology in an organisation (Orlikowski 2000). These enacted practices in KISU have implications on the processes and structure. For instance, to enable the organisational practice, KISU had to upgrade the call centre so they can receive queries from social media platforms. Also, the new enacted practices have influenced the organisation to outsource some of the practices associated with social media to fill the skill deficiency within the organisation. For example, when exploring the outsourcing of social media, you will discover that the organisation does not contain that position in its organogram and this explains why they do have a skills gap on running the social media. Given that KISU's structure is centralised with formal elements, 
some changes in the structure cannot occur quickly because of the rigidity influenced by bureaucracy. Nevertheless, the influence of social media practices on the structure is likely to happen when the organisational structure is revisited. Therefore, taken together, all this suggests that the social media practices enact process and structure in an imbricative manner, whereas the new processes and structure contain many elements from the pre-existing ones (Leonardi 2011). Considering that the effect of these practices on a structure is hardly seen compared to the effect on process, this suggests that the imbrication of process occurs faster than the imbrication of a structure. This refers us back to Piskorski's (2014) tactical suggestion that processual (functional) changes are easier to implement, but they are short-term benefits, while structural changes need a company-wide strategy, as they are complex in implementation. Figure 4 demonstrates the imbrication of processes with the example of the call centre in KISU:

Figure 4 demonstrates the imbrication of processes, which shows that new processes within the organisation contain a lot of elements from the pre-existing process. Also, it indicates that processes, structure and strategy occur in an emergent nature. Ciborra (2006) suggests that imbrication captures the reciprocal, self-reinforcing, often non-linear impacts of one representation upon the other. Thus, activities by multiple players within and outside the organisation such as online communities, context, invigorated processes and enacted practices all contribute in a numerous and diverse way to the emergence of social media strategy in KISU.

Our second research question aimed to examine how an organisation uses social media to enhance competitiveness. The implemented social media strategy was based on mimicking the social media practices of competitors as a means of sustaining competitiveness. The imitation strategy replicated practices of competitors with few alterations based on competitors' weaknesses and was a means of maintaining similarity between competitive organisations. The praxis element of strategy as practice emphasises the meaning-making (interpretation) of practitioners as observed in the actual activities (Huang et al. 2014). The marketing manager and product development manager reason that if you want to survive the competition, you should mimic the activities so that you are not left behind by competitors. The imitation strategy corresponds with Sinclaire and Vogus 2011suggestion that organisations tend to mimic so they do not lose their competitiveness. Similarly, Braojos-Gomez et al. (2015) suggest social competitor pressures as a cause for organisations to choose an imitation strategy as a means to enhance their competitiveness.

In addition to the above, KISU entwining its products with social media is significant in enhancing KISU's competitiveness. This makes the product development strategy a key means for sustaining the competitiveness of the telecom organisation. The products developed in telecom organisations consider the market, technological and customer demands. The customer who demands products that have social media elements provide meaning to the entwinement of product and social media, consequently producing its relevance to competitiveness. Similarly, Liu et al. (2005) suggest that organisations tend to develop their products with new technology to cope with customers' demands and threats from competitors. In addition to this, Aswani et al. (2017) suggest that organisations tend to use social media profiles for content promotion and knowledge dissemination centred in products and services. Thus, the product development strategy that is emerging here due to social media influence is necessary to make the telecom company survive the changes.

Overall, the discussion above shows the diverse influence of social media on different strategic practices that enhance organisational competitiveness of KISU. The practices seen in KISU are socially situated (Jarzabkowski 2005), which enact processes and structure (Orlikowski 2000) in an imbricative manner (Leonardi 2011). Specifically, this paper contributes to organisational adaptation through the imbrication of processes which occurs often compared to imbrication of a structure. The next section is going to discuss further this contribution, its implication on literature as well as on practice.

\subsection{Contribution to Literature}

This research contributes to the literature on organisational change (Burke 2017) with the imbrication of processes which highlights the strong influence of social media on processes compared to structure. Our study has shown how processes emerge in an imbricative manner while the structure continues to endure for a longer period. This indicates that the speed of

Fig. 4 Imbrication process

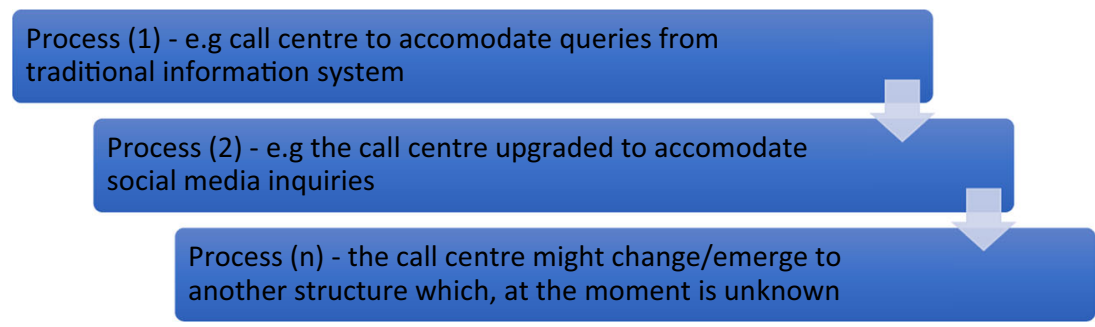


change in processes is greater compared to a change in structure. Also, this might suggest that the influence of technology on processes is faster while on structure it is gradual. Through this, it adds to the literature on social media strategy by explicating Piskorski's (2014) tactical choices, of why it is more appealing for organisations to implement social media strategy in some functional areas before executing it on a companywide level. This is usually because organisations can efficiently support social media strategy in functions that tend to have a significant impact. Nevertheless, structure limits and enables strategy (Whittington 2010); our contribution suggests that organisations should consider structural changes to implement social media strategy on the company-wide level successfully. Also, this echoes the findings of Dwivedi et al. (2015) which assert that regarding the scope and reach for many IT projects, regardless of how sophisticated they are, their impact depends on the broader institutional (structural) changes within the organisation.

This paper also contributes to the literature by bringing forward the context of Tanzania - a part of the developing world. Following the strategy as practice perspective which considers strategy as a situated activity (Jarzabkowski 2005), this paper demonstrates how social media strategy in telecom organisations is unique to the Tanzanian society; for instance, the idea of providing 'free social media'. Situated practices such as this are activities which shape and are shaped by the society within which they occur. The 'free social media' strategy is explained by the arrangement of infrastructure that supports social media usage (which are internet infrastructure and mobile development) within Tanzania. A contribution like this is significant to the IS phenomena as it highlights how technology such as social media can have a different application and impact when it is used within the context of emerging markets, hence working towards reducing the digital divide (Mercer 2005).

Finally, this study has highlighted how social media, when embedded in an organisational context, extends the role of information systems within the organisation. The paper has shown how social media revitalises important fundamental processes within organisations such as information sharing and feedback response from staff and customers. Thus, under the umbrella of the strategy as practice perspective, this continues to signify how people find affordances (Treem and Leonardi 2012) of technology in their situated environment/ organisational context (Jarzabkowski 2005; Orlikowski 2000).

This contribution may have several implications to practice as will be explained in the next section.

\subsection{Implications for Practice}

This study has the following insights for practitioners. Firstly, the management of organisations must learn to be receptive to new changes. This study has shown that changes emerge fast, especially in processes. Thus, organisations must be flexible to allow new practices that tend to accommodate new needs of carrying out the processes. For example, the new imbricated processes might not be significant, but with time they may gain significance. For example, the queries originating from social media may increase in size when more people use social media and perhaps the questions arising from other means might decrease. Therefore, flexibility can be enhanced when an organisation is quick to adopt and learn new processes which are enacted.

Secondly, organisations should enhance collaboration between different departments and actors within and outside the organisation. The study has shown how different departments function to facilitate the smooth operation of social media platforms. A robust collaboration between departments provides a synergy for organisations to exploit the full potential of social media platforms. Also, collaboration enables the organisation to evade risks associated with social media platforms.

Thirdly, the findings of this study suggest that organisations should invest in research, development and training. Investing in research and developing staff through training will help to develop new sets of skills and capabilities that are essential for emerging processes within organisations. Some of the new processes emerge because social media requires a new set of skills and capabilities. Organisations can leverage social media more when they do have the skills and capabilities inside the organisation rather than depending on external sources to fill the gap.

Finally, organisations may fail to compete and capture the potential business value from social media platforms when they fail to accommodate changes, coordinate actors, and invest in the skills and capabilities of their staff. The market is changing so the structure and processes of organisations should change to allow new practices associated with social media to enhance competitiveness. If the organisation fails to change with the needs of the market, the market will exterminate the organisation. Serving new markets on new platforms requires a new set of skills and capabilities which contain new structure and processes. Thus, it is important for an organisation to be flexible, receptive to change, leverage the synergetic power of practitioners and invest in the practitioner's skills.

\section{Conclusion}

This paper set to explore how social media enhances competitiveness using the strategy as practice perspective. The objective was to understand how social media influences the emergence of strategy, structure and processes, as well as how organisations use social media to enhance competitiveness. The paper started by exploring different concepts in social media strategy and the relationship between technology, 
strategy, structure and processes. From the case study of a Tanzania telecom company, the study establishes how practices associated with social media enhanced the competitiveness of the company. Specifically, competitiveness was enhanced by imitation and the product development strategy. Also, social media practices within the case organisation enacted processes and structure in an imbrication manner, although not simultaneously. This finding significantly contributes to IS literature through showing that social media has a faster rate of impacting the processes relative to the structure. Furthermore, it adds to the understanding of the tactical choice of implementing social media strategy in the organisation.

\subsection{Limitations and Future Research}

Although our study has provided fresh insights on how social media impacts strategy, structure and processes, it has not been able to show the effect of social media on structure (which endures for long) since the study was not longitudinal. Future longitudinal studies could prove fruitful, considering that Dwivedi et al. (2015) suggest that longitudinal studies will help to document and explain the processes by which misalignments between IT project such as social media and institutional practices are resolved. Thus, it can help understand how structural changes happen to embed the new practices associated with social media. Future research may explore the influence of social media on organisational structure over an extended period; this will shed more light on the speed in which imbrication of structure occurs. Additionally, further empirical research on digital technologies and social media can help to further our understanding of how structure enables and constrains social media strategies for competitiveness. Moreover, a similar study which compares different contexts, or with multiple cases, will provide more insight on this topic.

Open Access This article is distributed under the terms of the Creative Commons Attribution 4.0 International License (http:// creativecommons.org/licenses/by/4.0/), which permits unrestricted use, distribution, and reproduction in any medium, provided you give appropriate credit to the original author(s) and the source, provide a link to the Creative Commons license, and indicate if changes were made.

\section{References}

Aral, S., Dellarocas, C., \& Godes, D. (2013). Introduction to the special issue - Social media and business transformation: A framework for research. Information Systems Research, 24(1), 3-13. https://doi. org/10.1287/isre.1120.0470.

Archer, M., Lawson, T., \& Norrie, A. (2013). Critical realism: Essential readings. Abingdon: Routledge.

Ashkenas, R., Ulrich, D., Jick, T., \& Kerr, S. (2015). The boundaryless organization: Breaking the chains of organizational structure. Hoboken: Wiley.
Aswani, R., Kar, A. K., \& Ilavarasan, P. V. (2017). Detection of spammers in twitter marketing: a hybrid approach using social media analytics and bio inspired computing. Information Systems Frontiers. https:// doi.org/10.1007/s10796-017-9805-8.

Avgerou, C. (2017). Theoretical Framing of ICT4D Research. In J. Choudrie, M. Islam, F. Wahid, J. Bass, \& J. Priyatma (Eds.), Information and Communication Technologies for Development. ICT4D 2017, IFIP advances in information and communication technology, vol 504. Cham: Springer.

Belasen, A., \& Rufer, R. (2013). Innovation communication and interfunctional collaboration: A view from the competing values framework for corporate communication. In Strategy and Communication for Innovation (pp. 227-240). Berlin Heidelberg: Springer. https:// doi.org/10.1007/978-3-642-41479-4 14.

Berthon, P. R., Pitt, L. F., Plangger, K., \& Shapiro, D. (2012). Marketing meets web 2.0, social media, and creative consumers: Implications for international marketing strategy. Business Horizons, 55(3), 261271. https://doi.org/10.1016/j.bushor.2012.01.007.

Bharati, P., Zhang, C., \& Chaudhury, A. (2014). Social media assimilation in firms: Investigating the roles of absorptive capacity and institutional pressures. Information Systems Frontiers, 16(2), 257272. https://doi.org/10.1007/s10796-013-9433-x.

Braojos-Gomez, J., Benitez-Amado, J., \& Llorens-Montes, F. J. (2015). How do small firms learn to develop a social media competence? International Journal of Information Management, 35(4), 443-458. https://doi.org/10.1016/j.ijinfomgt.2015.04.003.

Bryman, A., \& Bell, E. (2015). Business research methods. USA: Oxford University Press.

Bughin, J., \& Chui, M. (2013). Evolution of the networked enterprise: McKinsey global survey results. McKinsey Quarterly, 29, 34-41.

Burke, W. W. (2017). Organization change: Theory and practice. Thousand Oaks: Sage Publications.

Castelló, I., Etter, M., \& Årup Nielsen, F. (2016). Strategies of legitimacy through social media: The networked strategy. Journal of Management Studies, 53(3), 402-432. https://doi.org/10.1111/ joms. 12145 .

Cecez-Kecmanovic, D., Galliers, R. D., Henfridsson, O., Newell, S., \& Vidgen, R. (2014). The sociomateriality of information systems: Current status, future directions. MIS Quarterly, 38(3), 809-830. https://doi.org/10.25300/MISQ/2014/38:3.3.

Ciborra, C. (2006). Imbrication of representations: Risk and digital technologies. Journal of Management Studies, 43(6), 1339-1356. https://doi.org/10.1111/j.1467-6486.2006.00647.x.

Coffey, A., \& Atkinson, P. (1996). Making sense of qualitative data: Complementary research strategies. Thousand Oaks: Sage Publications, Inc..

Culnan, M., mchugh, P., \& Zubillaga, J. (2010). How large u.S. companies can use twitter and other social media to gain business value. MIS Quarterly Executive, 9(4), 243-259.

Dewan, S., \& Ramaprasad, J. (2014). Social media, traditional media, and music sales. MIS Quarterly, 38(1), 101-121. https://doi.org/10. 25300/MISQ/2014/38.1.05.

Dwivedi, Y. K., Rana, N. P., Jeyaraj, A., Clement, M., \& Williams, M. D. (2017). Re-examining the unified theory of acceptance and use of technology (UTAUT): towards a revised theoretical model. Information Systems Frontiers. https://doi.org/10.1007/s10796017-9774-y.

Dwivedi, Y. K., Wastell, D., Laumer, S., Henriksen, H. Z., Myers, M. D., Bunker, D., Elbanna, A., Ravishankar, M. N., \& Srivastava, S. C. (2015). Research on information systems failures and successes: Status update and future directions. Information Systems Frontiers, 17(1), 143-157. https://doi.org/10.1007/s10796-014-9500-y.

Gallaugher, J., \& Ransbotham, S. (2010). Social media and customer dialog management at Starbucks. MIS Quarterly Executive, 9(4), 197-212. 
Gangi Di, P. M., Johnston, A. C., Worrell, J. L., \& Thompson, S. C. (2016). What could possibly go wrong? a multi-panel Delphi study of organizational social media risk. Information Systems Frontiers. https://doi.org/10.1007/s10796-016-9714-2.

Giddens, A. (1984). The constitution of society: Outline of the structuration theory. Cambridge: Polity.

Glaser, B., \& Strauss, A. (1967). The discovery of grounded theory. 1967 (pp. 1-19). London: Weidenfield \& Nicolson.

GlobalStats. (2017). http://gs.statcounter.com/social-media-stats/all/ tanzania/\#monthly-201610-201709-bar. Accessed 28 May 2017.

Golsorkhi, D., Rouleau, L., Seidl, D., \& Vaara, E. (Eds.). (2015). Cambridge handbook of strategy as practice. Cambridge: Cambridge University Press. https://doi.org/10.1017/ CBO9781139681032.

Harper, C. (2015). Organizations: Structures, processes and outcomes. Abingdon: Routledge.

Harris, D. A., Kaefer, F., \& Salchenberger, L. M. (2013). The development of dynamic capabilities through organisational and managerial processes. International Journal of Business Environment, 5(4), 398-412. https://doi.org/10.1504/IJBE.2013.052087.

Huang, J., Newell, S., Huang, J., \& Pan, S. L. (2014). Site-shifting as the source of ambidexterity: Empirical insights from the field of ticketing. The Journal of Strategic Information Systems, 23(1), 29-44. https://doi.org/10.1016/j.jsis.2014.01.001.

Idemudia, E. C., Raisinghani, M. S., \& Samuel-Ojo, O. (2016). The contributing factors of continuance usage of social media: An empirical analysis. Information Systems Frontiers, 1-14.

Internet world Stats. (2017). http://www.internetworldstats.com/stats1. htmAppendix. Accessed 28 May 2017.

Jarzabkowski, P. (2005). Strategy as practice: An activity based approach. Newcastle upon Tyne: Sage.

Joos, J. G. (2008). Social media: new frontiers in hiring and recruiting. Employment Relations Today, 35(1),51-59.

Jarzabkowski, P., Balogun, J., \& Seidl, D. (2007). Strategizing: The challenges of a practice perspective. Human relations, 60(1), 5-27. https://doi.org/10.1177/0018726707075703.

Kaplan, A. M., \& Haenlein, M. (2011). Two hearts in three-quarter time: How to waltz the social media/viral marketing dance. Business Horizons, 54(3), 253-263. https://doi.org/10.1016/j.bushor.2011. 01.006 .

Kapoor, K. K., Tamilmani, K., Rana, N. P., Patil, P., Dwivedi, Y. K., \& Nerur, S. (2017). Advances in social media research: past, present and future. Information Systems Frontiers. https://doi.org/10.1007/ s10796-017-9810-y.

Kietzmann, J. H., Hermkens, K., McCarthy, I. P., \& Silvestre, B. S. (2011). Social media? Get serious! Understanding the functional building blocks of social media. Business Horizons, 54(3), 241251. https://doi.org/10.1016/j.bushor.2011.01.005.

Lawton, T. C. (2017). Cleared for take-off: Structure and strategy in the low fare airline business. Abingdon: Routledge.

Leonardi, P. M. (2011). When flexible routines meet flexible technologies: Affordance, constraint, and the imbrication of human and material agencies. MIS Quarterly, 35(1), 147-167. https://doi.org/10. 2307/23043493.

Leonardi, P. M. (2015). Ambient awareness and knowledge acquisition: Using social media to learn "who knows what" and "who knows whom”. MIS Quarterly, 39(4), o747-o762.

Leonardi, P., \& Vaast, E. (2016). Social media and their affordances for organizing: a review and agenda for research. Academy of Management Annals, 11(1),150-188. https://doi.org/10.5465/ annals.2015.0144.

Liu, P. L., Chen, W. C., \& Tsai, C. H. (2005). An empirical study on the correlation between the knowledge management method and new product development strategy on product performance in Taiwan's industries. Technovation, 25(6), 637-644. https://doi.org/10.1016/j. technovation.2003.11.001.
Luo, X., Zhang, J., \& Duan, W. (2013). Social media and firm equity value. Information Systems Research, 24(1), 146-163. https://doi. org/10.1287/isre.1120.0462.

Mercer, C. (2005). Telecentres and transformations: Modernizing Tanzania through the internet. African Affairs, 105(419), 243-264.

Mof. (2017). http://www.mof.go.tz/mofdocs/Micro/2012/ECONOMIC\% 20SURVEY\%20BOOK\%202012.pdf Accessed 28 May 2017.

Muhammad, S. S., Dey, B. L., \& Weerakkody, V. (2017). Analysis of factors that influence customers' willingness to leave big data digital footprints on social media: a systematic review of literature. Information Systems Frontiers. https://doi.org/10.1007/s10796017-9802-y.

Orlikowski, W. J., \& Scott, S. V. (2008). Sociomateriality: Challenging the separation of technology, work and organization. The Academy of Management Annals, 2(1), 433-474. https://doi.org/10.1080/ 19416520802211644

Orlikowski, W. J., \& Baroudi, J. J. (1991). Studying information technology in organizations: Research approaches and assumptions. Information Systems Research, 2(1), 1-28. https://doi.org/10.1287/ isre.2.1.1.

Orlikowski, W. J. (2000). Using technology and constituting structures: A practice lens for studying Technology in Organizations. Organization Science, 11(4), 404-428. https://doi.org/10.1287/ orsc.11.4.404.14600.

Orlikowski, W. J. (2007). Sociomaterial practices: Exploring technology at work. Organization Studies, 28(9), 1435-1448. https://doi.org/10. 1177/0170840607081138.

Pan, S. L., \& Tan, B. (2011). Demystifying case research: A structuredpragmatic-situational (SPS) approach to conducting case studies. Information and Organization, 21(3), 161-176. https://doi.org/10. 1016/j.infoandorg.2011.07.001.

Parveen, F., Jaafar, N. I., \& Ainin, S. (2015). Social media usage and organizational performance: Reflections of Malaysian social media managers. Telematics and Informatics, 32(1), 67-78. https://doi.org/ 10.1016/j.tele.2014.03.001.

Pillet, J. C., \& Carillo, K. D. A. (2016). Email-free collaboration: An exploratory study on the formation of new work habits among knowledge workers. International Journal of Information Management, 36(1), 113-125. https://doi.org/10.1016/j.ijinfomgt. 2015.11.001.

Piskorski, M. J. (2014). A social strategy: How we profit from social media. Princeton: Princeton University Press. https://doi.org/10. 1515/9781400850020.

Porter, M. E. (2008). Competitive advantage: Creating and sustaining superior performance. New York: Simon and Schuster.

Rana, N.P., Dwivedi, Y.K., Lal, B., Williams, M.D. and Clement, M., 2017. Citizens' adoption of an electronic government system: Towards a unified view. Information Systems Frontiers, 19(3), pp. 549-568.

Richey, M., Gonibeed, A., \& Ravishankar, M. N. (2018). The perils and promises of self-disclosure on social media. Information Systems Frontiers. https://doi.org/10.1007/s10796-017-9806-7.

Saunders, M., Lewis, P., \& Thornhill, A. (2009). Research methods for business students, 5th ed. Edinburgh: Pearson Education.

Scott, S. V., \& Orlikowski, W. J. (2012). Reconfiguring relations of accountability: Materialization of social media in the travel sector. Accounting, Organizations and Society, 37(1), 26-40. https://doi. org/10.1016/j.aos.2011.11.005.

Scott, S., \& Orlikowski, W. (2014). Entanglements in practice: performing anonymity through social media. MIS Quarterly, 38(3), 873-893. https://doi.org/10.25300/misq/2014/38.3.11.

Sedoyeka, E., Hunaiti, Z., Al Nabhan, M., \& Balachandran, W. (2008). March. WiMAX mesh networks for underserved areas. In Computer Systems and Applications, 2008. AICCSA 2008. IEEE/ACS International Conference on (pp. 1070-1075). IEEE. 
Sinclaire, J. K., \& Vogus, C. E. (2011). Adoption of social networking sites: An exploratory adaptive structuration perspective for global organizations. Information Technology and Management, 12(4), 293-314. https://doi.org/10.1007/s10799-011-0086-5.

Stonehouse, G., \& Snowdon, B. (2007). Competitive advantage revisited: Michael porter on strategy and competitiveness. Journal of Management Inquiry, 16(3), 256-273. https://doi.org/10.1177/ 1056492607306333.

Takahashi, N. (2017). Ownership structure follows managerial strategy. Annals of Business Administrative Science, 16(2),77-89. https://doi.org/10.7880/abas.0170125a.

TCRA. (2017). https://www.tcra.go.tz/images/documents/ telecommunication/CommStatSept17.pdf. Accessed 13 Oct 2017.

Treem, J. W., \& Leonardi, P. M. (2012). Social media use in organizations: Exploring the affordances of visibility, editability, persistence, and association. Communication Yearbook, 36, 143-189.

Wade, M., \& Hulland, J. (2004). The resource-based view and information systems research: Review, extension, and suggestions for future research. MIS Quarterly, 28(1), 107-142. https://doi.org/10.2307/ 25148626.

Wagner, C., Mannion, R., Hammer, A., Groene, O., Arah, O. A., Dersarkissian, M., Suñol, R., \& DUQuE Project Consortium. (2014). The associations between organizational culture, organizational structure and quality management in European hospitals. International Journal for Quality in Health Care, 26(suppl_1), 74-80.

Whittington, R. (2016). Emergent strategy. The Palgrave encyclopedia of. Strategic Management. https://doi.org/10.1057/978-1-349-948482 577-1.

Whittington, R. (2010). Giddens, structuration theory and strategy as practice. In D. Golsorkhi, L. Rouleau, D. Seidl, \& E. Vaara (Eds.), Cambridge handbook of strategy as practice (pp. 109-126). Cambridge: Cambridge University Press.

Whittington, R. (2014). Information systems strategy and strategy-aspractice: A joint agenda. The Journal of Strategic Information Systems, 23(1), 87-91. https://doi.org/10.1016/j.jsis.2014.01.003.
World bank. (2017). http://www.worldbank.org/en/country/tanzania/ overview. Accessed 28 May 2017.

Wu, J., Du, H., Li, X., \& Li, P. (2010). Creating and delivering a successful knowledge management strategy. Knowledge Management Strategies for Business Development, 261-276. https://doi.org/10. 4018/978-1-60566-348-7.ch012.

Yin, R. (2013). Case study research: design and methods, 5th ed. London: Sage Publication.

Shirumisha C Kwayu is a PhD student at Nottingham Trent University. His research topic explores the impact of social media on the alignment of strategies within organisations.

Dr. Banita Lal is a Senior Lecturer in Information Studies at the Nottingham Business School. Nottingham Trent University. She gained her PhD in Information Systems from Brunel University. Her research interests revolve around the adoption and diffusion of technology, including broadband, mobile and e-Government technology. Banita has published in leading peer-reviewed conferences and journals in the field of Information Systems, including Information Systems Frontiers, Government Information Quarterly and Information Technology and People.

Dr Mumin Abubakre is a Senior Lecturer in Management. He holds a $\mathrm{PhD}$ in Management Information Systems from Loughborough University. Mumin's research interests span culture and its interface with the implementation of e-business/IS strategies, Global Management of IT and digital entrepreneurship. Mumin has published articles in peerreviewed scholarly journals such as Information \& Management Journal, Information Technology \& People, Journal Global of Information Management. He is currently on the editorial board of Journal Global of Information Technology Management. 